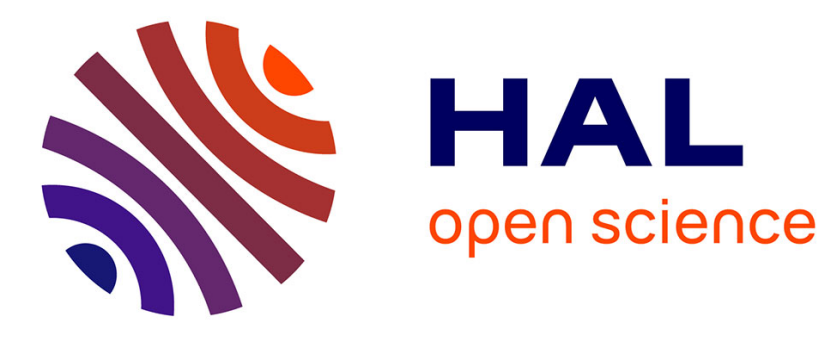

\title{
Size effects on melting and wetting in the $\mathrm{Ga}-\mathrm{Pb}$ nano-alloy \\ Marco Allione, Richard Kofman, Franck Celestini, Y. Lereah
}

\section{To cite this version:}

Marco Allione, Richard Kofman, Franck Celestini, Y. Lereah. Size effects on melting and wetting in the Ga-Pb nano-alloy. The European Physical Journal D : Atomic, molecular, optical and plasma physics, 2009, 52 (1-3), pp.207-210. 10.1140/epjd/e2009-00072-2 . hal-00434457

\section{HAL Id: hal-00434457 https://hal.science/hal-00434457}

Submitted on 11 Feb 2010

HAL is a multi-disciplinary open access archive for the deposit and dissemination of scientific research documents, whether they are published or not. The documents may come from teaching and research institutions in France or abroad, or from public or private research centers.
L'archive ouverte pluridisciplinaire HAL, est destinée au dépôt et à la diffusion de documents scientifiques de niveau recherche, publiés ou non, émanant des établissements d'enseignement et de recherche français ou étrangers, des laboratoires publics ou privés. 


\title{
Size effects on Melting and Wetting in the Ga-Pb Nano-Alloy
}

\author{
Marco Allione $_{-}^{1^{*}}$, Richard Kofman ${ }^{1}$, Franck Celestini ${ }^{1}$ and Yossi Lereah ${ }^{2,3}$ \\ ${ }^{1}$ Laboratoire de Physique de la Matière Condensée, Université de Nice Sophia Antipolis et \\ UMR CNRS N $N^{\circ}$ 6622, Parc Valrose, 06108 Nice Cedex 2, France \\ ${ }^{2}$ Wolfson Applied Materials Research Center, Tel-Aviv University, 69978 Tel-Aviv, Israel \\ ${ }^{3}$ Department of Physical Electronics, Faculty of Engineering, Tel-Aviv University, \\ 69978 Tel-Aviv, Israel
}

\begin{abstract}
:
$\mathrm{Ga}-\mathrm{Pb}$ alloys with $15 \mathrm{at} \% \mathrm{~Pb}$ mean concentration have been prepared at the nanoscale by means of evaporation-condensation technique in ultra high vacuum conditions. Transmission electron microscope images indicate that at room temperature, the system is a twocomponents breath figure composed of liquid $\mathrm{Ga}$ nanodrops containing $\mathrm{Pb}$ nanocrystals. Some thermodynamic properties of this nano-alloy are investigated for different temperatures and particle sizes. The results obtained put in evidence a large modification of the $\mathrm{Ga}-\mathrm{Pb}$ bulk phase diagram : a decrease of the melting points of the two components as well as the ones of the miscibility gap. Changes in the microscopic structure of the system as a function of temperature have been investigated and a full wetting transition from a dry to a completly wet state has been put in evidence.
\end{abstract}

\section{Introduction}

Metal nanoparticle composites are a very attracting subject of study since many years. Thermodynamics of nanostructured systems are studied since the very beginning, with the first results dating back to the nineteenth century [1]. It is now a well established result now that melting and solidification temperatures of metals are strongly modified in nanocomposites. In particular, it turns out that melting temperature is lowered with respect to the bulk one [2]. So far this property has been investigated in a large number of pure metals in different conditions of size and embedding matrices, but very little is known about metal alloys at nanoscale.

Metal alloys are extremely useful for the variability of their thermodynamical, mechanical and electrical properties that make them suitable for a very wide range of applications. The $\mathrm{Ga}-\mathrm{Pb}$ alloy system in particular is interesting for the structure of its phase diagram [3] as shown in Fig.1. $\mathrm{Ga}$ and $\mathrm{Pb}$ being quasi-immiscible at ambient temperature, the diagram shows the existence, between the bulk melting temperatures of the two metals, of two distinct phases, one represented by almost pure liquid $\mathrm{Ga}$, and the other by almost pure solid $\mathrm{Pb}$. Above the melting temperature $\left(327^{\circ} \mathrm{C}\right)$ the two liquids coexist for a wide range of temperature to finally mix at about $600^{\circ} \mathrm{C}$.

In a recent paper [4], we have investigated the fabrication of $\mathrm{Ga}-\mathrm{Pb}$ two-components breath figures. We showed that, by condensing $\mathrm{Ga}$ and $\mathrm{Pb}$ atomic vapours on a substrate, the system self-organises in a breath figure of $\mathrm{Ga}$ nanodrops containing each one a $\mathrm{Pb}$ nanocrystal. 


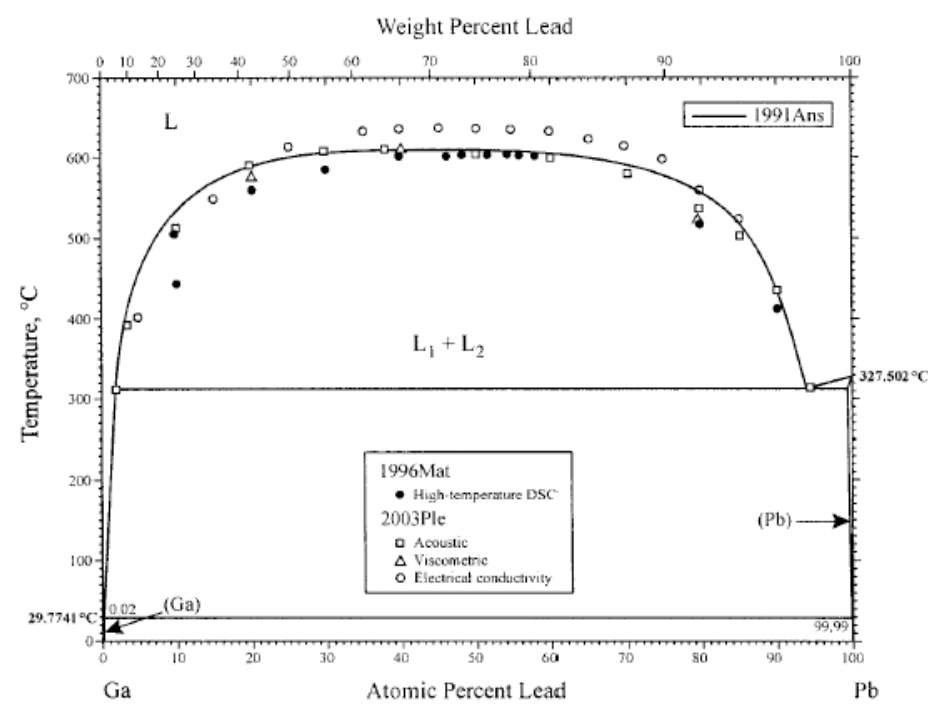

Figure 1. Ga- $\mathrm{Pb}$ bulk phase diagram.

In the same paper, we have obtained the $\mathrm{Pb}$ concentration in the $\mathrm{Ga}$ droplets and shown that it was dependent of size and different from the mean $\mathrm{Pb}$ concentration as deposited on the substrate.

In the present work, thermodynamic and structural properties of the Ga-Pb nano-system are investigated versus temperature with an aim of evaluating size effects on the $\mathrm{Ga}-\mathrm{Pb}$ phase diagram. We finally examine the wetting of $\mathrm{Pb}$ in a $\mathrm{Ga}$ nanodrop and put in evidence a transition from a completely dry to a completely wet state.

\section{Experiments}

Production of the $\mathrm{Ga}-\mathrm{Pb}$ breath figures has already been described [4]. The preparation technique allows the production of alloy nanoparticles of different concentration with average size ranging from few to few hundreds of nanometers. The samples obtained are studied by means of "in situ" electron microscopy with a field-effect cathode Tecnai F20 supplied with CCD and video cameras. Gatan heating and cooling holders were used for adjusting the temperature of the samples between $-160^{\circ} \mathrm{C}$ and $600^{\circ} \mathrm{C}$.

The microscope can be operated in different modes giving complementary informations as illustrated in Fig. 2.
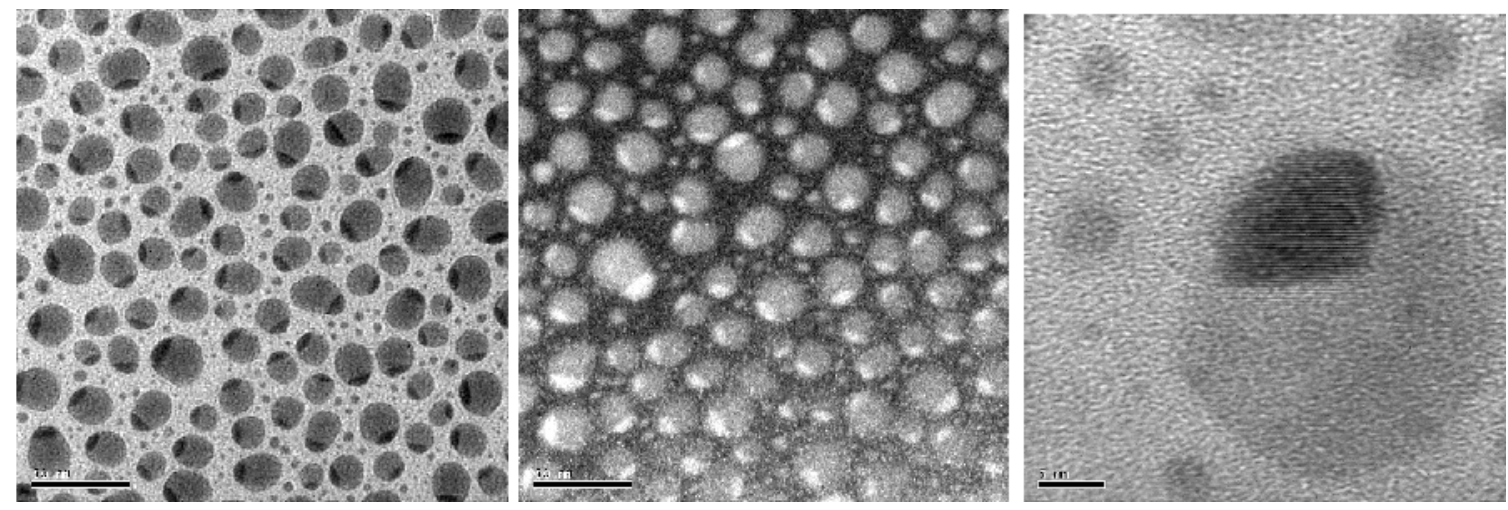

Figure 2: Left:bright field TEM image of a $\mathrm{Ga}-\mathrm{Pb}$ sample at $\mathrm{T}=202^{\circ} \mathrm{C}$. Center: dark field TEM image 
of the same sample at the same temperature. Right: high-resolution TEM image of a particle of the same sample at $\mathrm{T}=-160^{\circ} \mathrm{C}$ : we can easily distinguish the monocrystalline structure of the solid $\mathrm{Pb}$-rich phase, as well as its faceted shape.

Figure 2 on the left, displays the general appearance of the $\mathrm{Ga}-\mathrm{Pb}$ nanosystem as observed by TEM in bright field mode in the case of a sample $\mathrm{Ga}_{0.85} \mathrm{~Pb}_{0.15}$ corresponding to the successive deposition of $\mathrm{Ga}$ and $\mathrm{Pb}$ layers of respective equivalent thicknesses 3.2 and $0.8 \mathrm{~nm}$. We can easily distinguish the uniform contrast of $\mathrm{Ga}$ nanodrops and the diffraction contrast of $\mathrm{Pb}$ nanocrystals. The Ga nanodrops size distribution is bimodal [5], with a first mode characterized by a Gaussian distribution of droplet sizes and a second one given by a fast decaying tail of the smallest drops. In the main mode, whose Ga size is about $20 \mathrm{~nm}$, it is easy to observe the presence of $\mathrm{Pb}$ crystals of about $8 \mathrm{~nm}$ in size in contact with the $\mathrm{Ga} / \mathrm{SiO}_{\mathrm{x}}$ inner surface. As the solid $\mathrm{Pb}$ crystal diffracts electrons, it appears as a bright structure in dark field electron microscope image (central part) at the same magnification and same temperature. In the right part of Fig. 2 a high-resolution TEM is shown for a particle of the same sample at low temperature. The presence of a regular monocrystalline structure in the solid $\mathrm{Pb}$-rich core is clearly visible together with the faceted shape of the core. High resolution observations demonstrate also that no isolated $\mathrm{Pb}$ crystal is visible outside the Ga droplets.

\section{Results}

We focuss now on the results obtained for the sample with 15 at \% Pb. In Fig. 3, 12 TEM images of this sample are shown for temperatures ranging from -160 to $346^{\circ} \mathrm{C}$. Each picture concerns the same region of the sample but not exactly the same place, due to unavoidable drifts occuring during the increase of temperature..

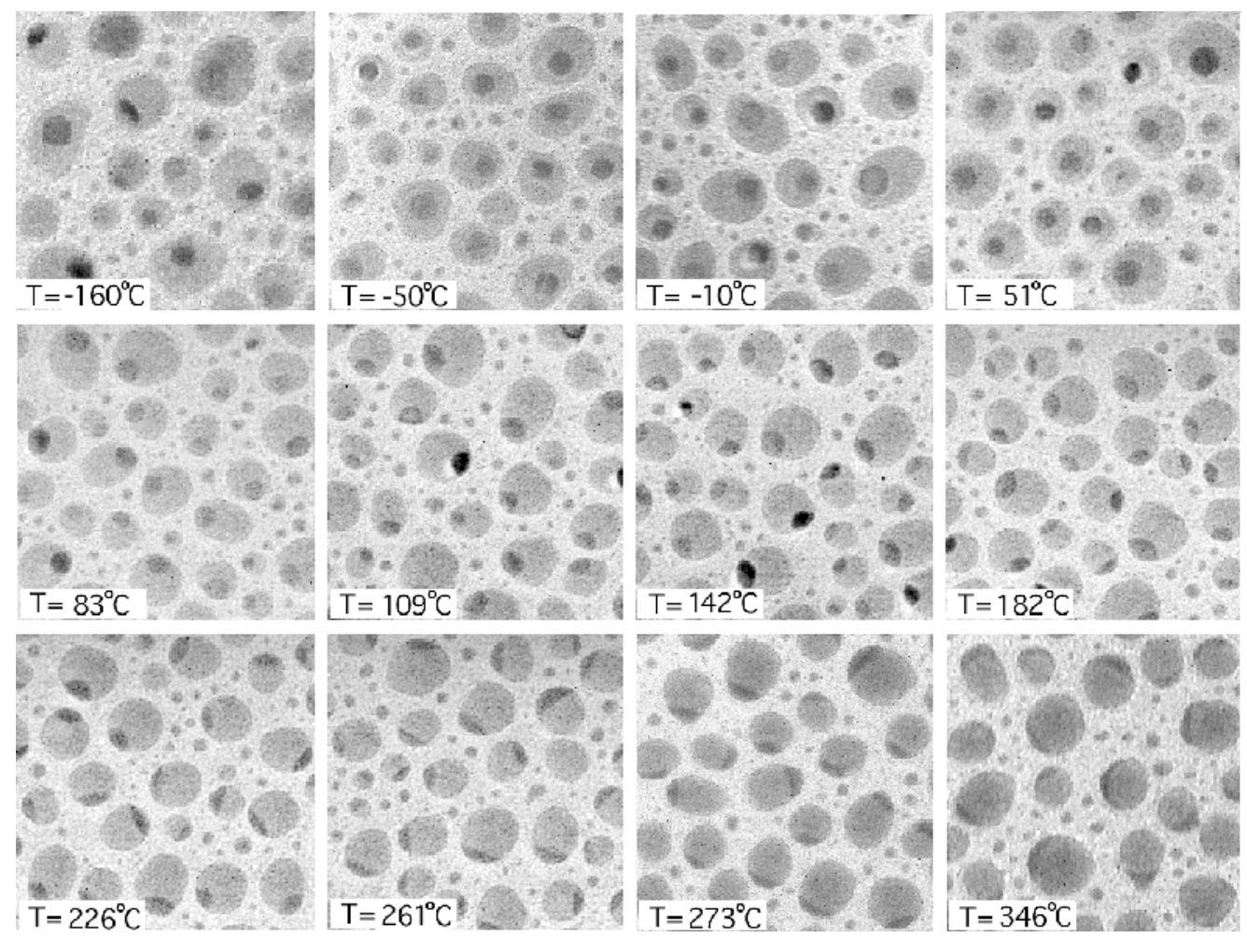


Figure 3: Bright-field TEM pictures illustrating the structure evolution of the $\mathrm{Ga}_{0.85} \mathrm{~Pb}_{0.15}$ sample with temperature. Each picture is a square of $120 \times 120 \mathrm{~nm}^{2}$.

Analysis of shapes and contrasts of the $\mathrm{Pb}$ particles, associated to a dark-field observation when necessary, allow to draw conclusions on the different phases of the system.

$\mathrm{Ga}$ beeing cooled from room temperature, at $\mathrm{T}=-160^{\circ} \mathrm{C}$ it can stay in a deep undercooled liquid state [6]. One can note that two Ga particles (in the upper part of the picture) have solidified. For higher temperatures $\mathrm{Ga}$ is in its liquid state.

For temperature below $51^{\circ} \mathrm{C}, \mathrm{Pb}$ is still solid inside liquid $\mathrm{Ga}$. We observe that $\mathrm{Pb}$ crystals have a cuboctaedron shape and are mainly located in the center of the Ga nanodrop. This suggests that $\mathrm{Pb}$ is mainly in contact with $\mathrm{Ga}$ and that there is not an extended $\mathrm{Pb} / \mathrm{SiOx}$ interface. Futhermore, in some cases, we observe a diffusive movement of the $\mathrm{Pb}$ crystal inside the nanodrop.

Above $83^{\circ} \mathrm{C}$ the situation is qualitatively changing since $\mathrm{Pb}$ crystals are now stuck at the $\mathrm{Ga} / \mathrm{SiOx}$ interface. We therefore clearly have a transition from a dry to wet state of $\mathrm{Pb}$ on $\mathrm{SiOx}$. We nevertheless cannot conclude on the continuous or discontinuous nature of this transition. It is important to note that the $\mathrm{Pb}$ is still in a solid phase with rounded facets at the $\mathrm{Pb} / \mathrm{Ga}$ interface. We do not know if we have a Liquid $\mathrm{Pb} / \mathrm{SiOx}$ or Solid $\mathrm{Pb} / \mathrm{SiOx}$ interface but we think that the onset of surface melting is at the origin of this transition to a wet state. As the temperature is increased the contact angle at the triple line between the $\mathrm{Pb}, \mathrm{Ga}$ and $\mathrm{SiOx}$ is clearly decreasing; this will be described in the next section.

Depending on their sizes, the melting temperature of $\mathrm{Pb}$ crystals is situated between 226 and $261{ }^{\circ} \mathrm{C}$. This result has been confirmed by high-sensitive optical measurements [2]. We will see in the next section that this melting has not a great influence on the wetting transition scenario, suggesting once again that the solid transition is broadened by surface melting and that we certainly have a Liquid $\mathrm{Pb} / \mathrm{SiOx}$ interface rather than a Solid $\mathrm{Pb} / \mathrm{SiOx}$ one.

As the temperature is increased the mixing between $\mathrm{Pb}$ and $\mathrm{Ga}$ becomes more an more important. Finally an homogeneus liquid state is reached at $443^{\circ} \mathrm{C}$ for all the particles. It is important to note that the transition is reversible while this is not the case fot solid-liquid $\mathrm{Pb}$ or Ga transitions for which a large hysteresis exist.

In the table 1 we summarize the characteristic temperatures of the phase transitions described just above and precise the quantitative differences with the bulk phase diagram. For all transition we roughly have in between 15 and $20 \%$ of relative variation. Note that Ga nanoparticles cristallize in a different phase (e.g. $\delta$ phase [6]) than the bulk $\alpha$ phase; this explains the high value found for the relative variation of the melting temperature.

\begin{tabular}{|c|c|c|c|}
\hline Transition & $\mathbf{T}_{\mathbf{c}}$ & $\mathbf{T}_{\text {bulk }}$ & $\left(\mathbf{T}_{\text {bulk }}-\mathbf{T}_{\mathbf{c}}\right) / \mathbf{T}_{\text {bulk }}$ \\
\hline Melting of Ga & $-34^{\circ} \mathrm{C}$ & $29.7^{\circ} \mathrm{C}$ & 0.21 \\
\hline Melting of $\mathrm{Pb}$ & From 226 to $261^{\circ}$ & $327.5^{\circ} \mathrm{C}$ & 0.16 \\
\hline Miscibility $\mathrm{Pb}$ and $\mathrm{Ga}$ & $443^{\circ} \mathrm{C}$ & $570^{\circ} \mathrm{C}$ & 0.15 \\
\hline
\end{tabular}

Table 1: Characteristic temperatures observed in the $\mathrm{Ga}_{0.85} \mathrm{~Pb}_{0.15}$ sample together with values of the bulk phase diagram and the associated relative variation. 
The contact angle $\theta$ at the triple line between the three phases (see inset in upper part of Fig. 4) can be measured to characterize the changes in wetting conditions versus temperature. An image analysis of bright-field TEM pictures of the sample has been done for 10 different temperatures in between 50.6 and $346^{\circ} \mathrm{C}$. For each temperature, at least 100 particles have been considered and their sizes range roughly in betwenn 10 and $30 \mathrm{~nm}$. Coordinates of the characteristic points of the $\mathrm{Ga}-\mathrm{Pb}$ meniscus have been recorded and analysed through a Fortran software that perrmits to extract the value of the contact angle $\theta$. In Fig. 4 we plot the size average contact angle as a function of the temperature. It is clear from this figure that $\theta$ is a decreasing function of $\mathrm{T}$, i. e that $\mathrm{Pb}$ is more an more wetting $\mathrm{SiOx}$ as the temperature is increased. Futhermore the system is undergoing a " fully continuous wetting transition » from a dry state to a completly wetting liquid $\mathrm{Pb}$. In the lower part of Fig. 4 we show four pictures illustrationg the transition described juste above. In the region of the $\mathrm{Pb}$ melting $\left(200<\mathrm{T}<250^{\circ} \mathrm{C}\right)$, we do not observe a large variation of the contact angle. This can be due to the size average value of the observed quantity and a more precise investigation is under progress.
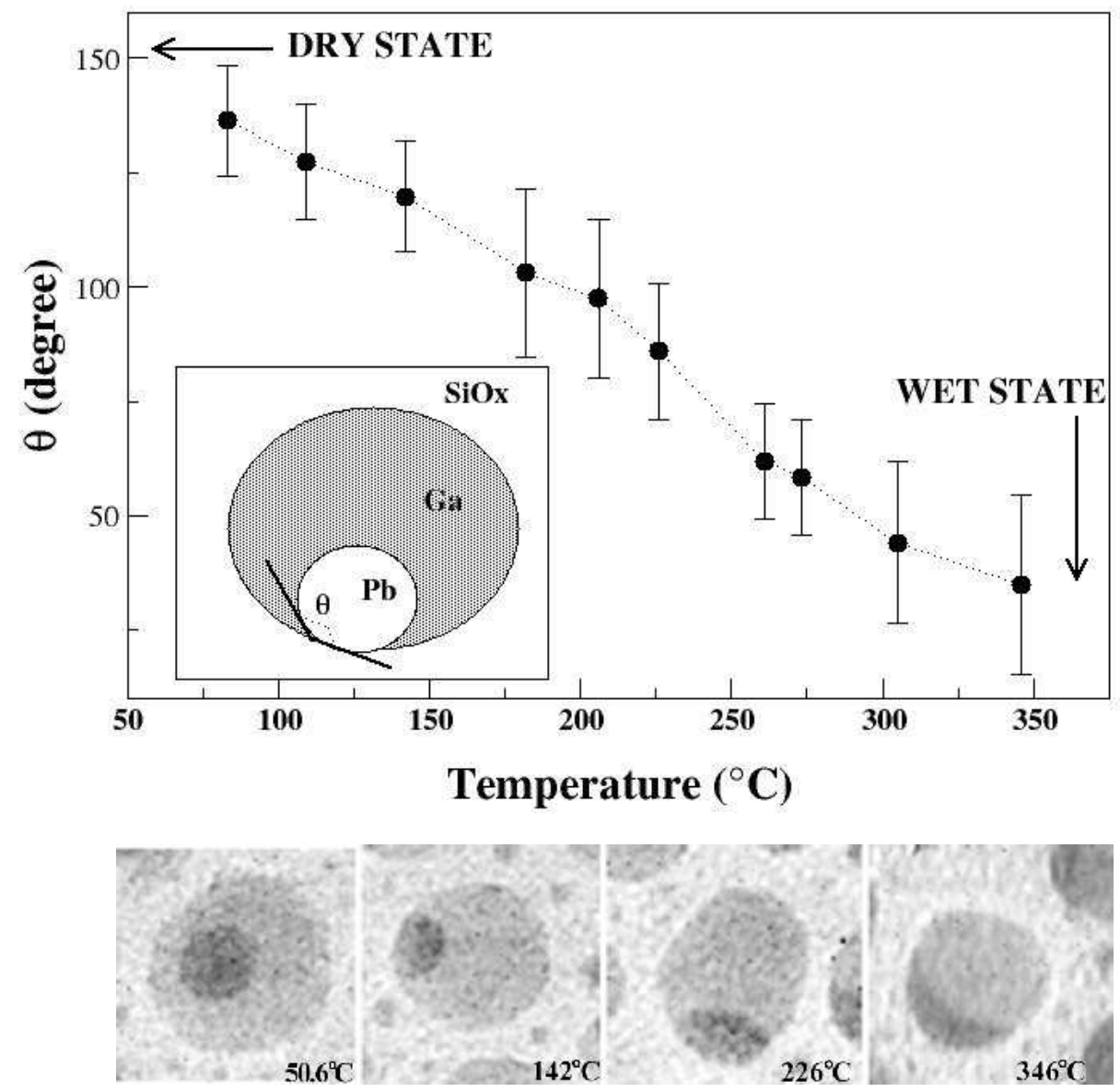

Figure 4: Temperature variation of the contact angle $\theta$ (as sketched in inset) at the triple line between the $\mathrm{Pb}, \mathrm{Ga}$ and $\mathrm{SiOx}$ phases. The pictures illustrate the shape evolution of the $\mathrm{Pb}$ phase when the temperature is increased (each picture is a square of $30 \times 30 \mathrm{~nm}^{2}$ ). 


\section{Conclusion}

In this paper, we have demonstrated that nanoscale $\mathrm{Ga}-\mathrm{Pb}$ alloys exhibit a phase diagram which is strongly different from the corresponding bulk one. The different values of the melting of $\mathrm{Ga}$, the melting of $\mathrm{Pb}$ and the miscibility temperatures are found to be lower than the bulk ones. In all cases the relative variation is in between 15 and $21 \%$.

An image analysis has been done to characterize the transition from the coexistence of $\mathrm{Ga}$ and $\mathrm{Pb}$ liquids to an homogeneous one. At low temperature the $\mathrm{Pb}$ is in contact with $\mathrm{Ga}$ but not with $\mathrm{SiOx}$ ( this is what we call a dry state). At $83^{\circ} \mathrm{C}$ the $\mathrm{Pb}$ starts to wet $\mathrm{SiOx}$, this onset of wetting could be due to the onset of surface melting of the $\mathrm{Pb}$ crystal. As the temperature is increased the contact angle is decreasing and the system finally reaches the homogeneous state. The state with a small but non zero value of $\theta$ corresponds to a full wetting of $\mathrm{Pb}$ on $\mathrm{SiOx}$. In that sense the presented results can be interpreted as a "fully continuous wetting transition" from a dry to a completely wet state. Previous work on larger Ga-Pb binary systems [7] has shown that Ga was completely wetted by $\mathrm{Pb}$, a qualitatively different result than the one presented here. A work is currently in progress to understand the differences observed. 
* Corresponding author, present adress : Italian Institute of Technology, via Morego 30, 16163 Genova, Italy

\section{$\underline{\text { References: }}$}

[1] - J.J.Thomson in "Applications of Dynamics to Physics and Chemistry", MacMillan, London (1888)

[2] - R. Kofman, F. Celestini, M. Allione and Y. Lereah in "Highlights on spectroscopies of semiconductors and nanostructures", G.Guizzetti, L.C.Andreani, F.Marabelli, M.Patrini

(Eds.), Societa Italiana di Fisica, Bologna, 94 (2007) 421

[3] - I. Ansara and F. Ajersch, J. Phase Equilibria 12, 73 (1991)

[4] - R. Kofman, M. Allione, F. Celestini, Z. Barkay and Y. Lereah, to appear in EPJD

[5] - E. Søndergard, R. Kofman, P. Cheyssac and A. Stella, Surface Science 364, 467 (1996)

[6] - A. Defrain, J. Chim. Phys. 74, 851 (1977)

[7] - D. Chatain and P. Wynblatt, Surface Sci. 345, 85 (1996) 